\title{
Information Seeking Behaviors, Attitudes, and Choices of Academic Mathematicians
}

\author{
Ian D. Gordon, Brian D. Cameron, Debbie Chaves \& Rebecca Hutchinson
}

To cite this article: Ian D. Gordon, Brian D. Cameron, Debbie Chaves \& Rebecca Hutchinson (2020) Information Seeking Behaviors, Attitudes, and Choices of Academic Mathematicians, Science \& Technology Libraries, 39:3, 253-280, DOI: 10.1080/0194262X.2020.1758284

To link to this article: https://doi.org/10.1080/0194262X.2020.1758284

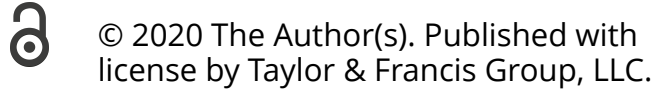

Published online: 05 Jun 2020.

Submit your article to this journal $\sqsubset$

ЏII Article views: 3460

Q View related articles $\square$

View Crossmark data ¿ 


\title{
Information Seeking Behaviors, Attitudes, and Choices of Academic Mathematicians
}

\author{
Ian D. Gordon (10), Brian D. Cameron $\mathbb{1}^{\mathrm{b}}$, Debbie Chaves $\mathbb{D}^{\mathrm{c}}$, \\ and Rebecca Hutchinson (10 ${ }^{d}$
}

aLiaison Services, Brock University, James A. Gibson Library, St. Catharines, Ontario, Canada; ${ }^{b}$ Collection Services, Ryerson University Library, Toronto, Ontario, Canada; 'User Services, Wilfrid Laurier University

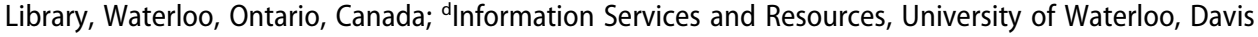
Centre Library, Waterloo, Ontario, Canada

\begin{abstract}
Mathematicians in academic institutions utilize a variety of resources and strategies to seek, find, and use scholarly information and news. Using a sample of mathematicians, researchers surveyed 112 students and faculty at four Canadian university institutions to explore self-perceived success rates, resources consulted, databases used, use of social media, and citation management systems. Further, 12 follow-up interviews were completed with mathematicians to better interpret survey results, resulting information-seeking behaviors, choices, strategies, and feelings on keeping up to date with information needs. According to survey results, a minority of mathematicians (12.5 percent) acknowledged that they were successfully keeping up to date. However, a significant number of mathematicians (28.6 percent) indicated that they were unsuccessful and could do better in remaining current with information needs. Co-investigators, using qualitative analyses, identified four emergent themes related to remaining current: (1) The "slower pace of math" pervades all aspects of this discipline;" (2) There are "too many papers - and not enough time" to effectively search, evaluate, and read scholarly papers of interest; (3) Mathematicians collectively acknowledge that they are open to strategies and technologies where they "could do better" keeping up to date; and (4) Mathematicians have divided loyalties using databases when searching for information by means of "MathSciNet in a Google world." Additional insights document how mathematicians are guided by mathematical peculiarities and discipline-specific practices. This study helps to shed light on opportunities for academic librarians to identify and meet mathematicians' evolving information needs.
\end{abstract}

\section{KEYWORDS}

Mathematicians; information-seeking behaviors; information needs; information sources; graduate students; faculty; academic (university) libraries; knowledge management

\section{Introduction}

How do mathematicians seek information, what resources do they consult, how successful are they, what behaviors do they exhibit, and how do they feel about these choices? These questions form the basis of this study as 
the second of a three-part research project investigating academic chemists (Gordon et al. 2018) and a forthcoming study that will investigate academic physicists. Researchers as academic librarians were also interested to observe idiosyncrasies specific to mathematicians' information seeking while commenting on similarities and differences observed within these scholarly groups.

Although mathematics transcends all physical sciences, mathematicians serving in academic settings naturally dig deeper into pure and applied mathematics, are dependent upon distinctive networks of colleagues and collaborators, and instinctively use mathematics as a universal language for scholarly communication. Mathematicians rely on mathematics and its specialized notations, conventions, and symbols to communicate abstract ideas and meaning when attempting to solve mathematical problems. Mathematicians likewise depend upon specialized journals, unique databases, subject-specific strategies, and unique means to communicate to stay on top of new and changing developments. Partially because of these distinctly mathematical ways of conducting research, mathematicians are thought to be set apart from other disciplines in their information needs, resources consulted, pace of development, and means of scholarly communication.

This study attempts to shed light on how mathematicians navigate their information-seeking worlds using a two-phased, mixed method methodology to create rich datasets and equally insightful findings. This study and its findings of observing and commenting on information behaviors as scholarship is important to a wide variety of stakeholder groups who could benefit in understanding mathematicians information-seeking behaviours.

\section{Literature review}

Information-seeking behavior refers to how humans perceive their need for, pursuit of, and use of information (Case and Given 2016). Information seeking as a social behavior occurs when an individual realizes the need to acquire contextual information and deliberately takes action to resolve that need (Agarwal 2018). These actions may include a variety of strategies including consulting colleagues, searching subject-specific and scholarly databases, and probing the Internet until this need is satisfied. The University of Toronto's Chun Wei Choo defined information-seeking behavior " $\ldots$ to refer to the patterns of behavior that people display as they recognize information needs, make choices about where and how to look for information, and reflect or act on the information they see" (Choo 2006, 41). Theoretical models have been advanced over the past thirty years that help conceptualize and describe these behaviors. Relatively recent reviews and critiques of information-seeking behaviors and models (Case and Given 2016; Choo 2006; Cole 2017; Falciani-White 2012; Fisher and Julien 2009; 
Jasen and Rieh 2010; Pettigrew, Fidel, and Bruce 2001; Robson and Robinson 2013; Savolainen 2018) continue to challenge David Ellis's groundbreaking information-seeking model (Ellis 1989a, 1989b, 1993; Ellis, Cox, and Hall 1993) that aligned seeking behaviors into slices of a seeking continuum. The following new and related studies (Dinet, Chevalier, and Tricot 2012; Falciani-White 2016; Fitzgerald 2018a, 2018b; Kuhlthau 1993, 2004) have built on Ellis's original information behavior model adding cognitive, affective, situational, integrative, and perceptual seeking elements.

Contemporary information-seeking debate has benefited from researchers using a variety of research methodologies to create more robust and authentic datasets. These datasets sought to explore and better understand the social dimensions of information seeking to further incorporate discipline-specific dimensions, context, perceptions, and individual's thoughts and feelings. This relatively new emphasis (Niu and Hemminger 2012; Niu et al. 2010; Shah 2017) seeks to better understand behaviors that press individuals toward different information-seeking behaviors taking into consideration demographic, cognitive, psychological, role-related, and environmental factors as determinants of information behavior.

Information seeking as a social phenomenon has been instrumental in identifying how academics communicate new ideas and comment on existing research. Observing how academics make information choices, and identify resources and strategies to stay on top of the literature is an important element of academic research. As a unique field of study, Donald Case and Lisa Given commented “... information behavior research has developed along multiple lines, and maintained its popularity. The field retains themes, theories, and methodologies from half a century past, and a few of these older approaches remain useful. At the same time it has embraced new perspectives, theories, and methods ... bodes well for the future" (Case and Given 2016, 365). Researchers investigating user-centered, discipline-specific professional, and academic roles have typically documented information-seeking strategies, preferences, and resources used in their normal research activities. Investigating how individuals use formal and informal networks and information resources is of interest to mathematicians as they seek out advice on how to unearth solutions to difficult, complex, and longstanding mathematical problems. Although an important component of mathematical research, the literature is relatively silent on how mathematicians in their roles remain current, seek, use, and incorporate information into their research.

Current researchers have increasingly studied unique populations, practitioners, and user groups. These groups include a wide swath of disciplines, populations, and professionals such as engineers and scientists (Wellings and Casselden 2019), physical scientists (Brown 1999), astrophysicists (Sahu and Nath Singh 2013), faculty (Anglada and Borrego 2016), public health researchers (Hunt and Bakker 2018), academic researchers (Nicholas et al. 
2017), graduate students (Bussell, Hagman, and Guder 2017; Catalano 2013; Jordan 2013) post-graduate fellows (Khazer and Ganaie 2018), and increasingly multidisciplinary researchers (Ge 2010; Greenberg and Bar-Ilan 2017; Wilson 1997). Gordon et al. (2018) investigated the information-seeking behaviors of academic chemists and found that a significant number of chemists (28.6\%) indicated that they were unsuccessful and could do better in remaining current, utilized a variety of strategies and resources, leaned toward using Google-based tools, and commented that there is too much information coming down the pipeline, and not enough time to evaluate it properly. These grounded, situational, user-centered, and integrative studies are valuable in documenting group-specific contextual frameworks and unique disciplinary practices.

A relatively recent study (Sapa, Krakowska, and Janiak 2014) investigated how academic mathematicians explored selected aspects of information seeking while searching the Internet for resources for their teaching, research, and learning activities. These researchers' findings mirrored other studies in that mathematicians were found to initially use search engines including Google as information-seeking starting points. Researchers typically searched resources using a combination of author's names and keywords. A minority of mathematicians declared MathSciNet to be their preferred scientific portal for subject-related research.

More recently, new studies have pushed the boundaries of informationseeking research to incorporate qualitative methodologies that are increasingly considerate of the emotional and unconscious aspects of information searching, underlying cognitive activity, various contextual and social factors. These types of studies (Pontis et al. 2017) create empirical evidence that points to information-seeking best practices, exposes gaps, weaknesses, and opportunities for discovery that can inform information services, professionals, and experts in practical ways. Gordon et al. (2018) investigating academic chemists found that a significant number of academic chemists exhibited identifiable behaviors. These behaviors included utilizing Google-like searching engines, overseeing more-appropriate discipline-related databases, search engines, social media, new technologies, and patents. Chemists at times were found to be indifferent to essential scholarly resources, felt overwhelmed by the amount of data and tasks at hand, inundated with different technologies and strategies to stay on top, and vulnerable to knowing best how to effectively search, evaluate, and manage information. Mathematicians, although distinctive in the ways they deal with keeping on top of information in their fields, may share these same behaviors and associated feelings.

Mathematics, analogous to numbers and counting, is all-pervasive, and "... part of almost every aspect of everyday life" (National Research Council 2013, 22). Additionally, mathematics is often described as being equally beautiful, complex, simple, difficult, powerful, constantly evolving, 
intriguing, fascinating, and misunderstood. A number of scholarly resources have eloquently described 'mathematical' perspectives that help to better understand and appreciate how mathematicians think (Brown 1985; Byers 2007; Dehaene 1997; Fitzgerald and James 2007; Hadamard 1996; Mason, Burton, and Stacey 2010; Ruelle 2007), perceive themselves (Casazza, Krantz, and Ruden 2015; Hersh and John-Steiner 2011), experience their worlds (Davis, Hersh, and Marchisotto 2012; Erickson 2011; Walliman 2017), and articulate the impact of mathematical research and scholarship over time (Heaton 2017; Hoyles and Wilson 2016; Tegmark 2014). In an era of big data, text mining, automated search engines, and an ambitious transition from human to machine-based information-seeking algorithms, observing and asking mathematicians how they do their research, who, and what they consult, why this is important and how they feel about these choices is paramount of importance.

Mathematicians are observed to be productive, logical, deductive thinkers, active and self-reliant information seekers. Their information-seeking behaviors, whether as novices or experts, are shaped by their environment, colleagues, and disciplinary resources.

Mathematicians as graduate students writing a dissertation or thesis, faculty members chasing the solution to a detailed problem, writing a grant proposal, or staff members wanting to probe current mathematical theorems or proofs, face behavioral, cognitive, technical, and subject-specific challenges. General information-seeking studies comment on the complexity and difficulty of staying on top of the literature in all disciplines, but it is difficult to postulate on information-seeking behaviors, strategies, and choices specific to mathematical communities.

To best understand mathematician's information-seeking behaviors it is essential to appreciate mathematics as a scholarly- and problem-driven activity that has mathematicians of all abilities, experience and subjects chasing solutions to elusive mathematical problems.

Solving problems is both the antithesis and bane of every mathematician's existence. Mathematicians' work is usually understandable only to a small group of specialists, involves small and closed communities or researchers, is a passionate pursuit, and periodically pervades their research, teaching, and service. Success is primarily determined by the extent which he/she can discover new finite facts and solutions about boundless problems. Mathematicians for time immortal have loved this journey, its challenges, and triumphs. Brock University's Bill Ralph best described the never-ending quest that drives mathematicians and their information-seeking behaviors when commenting, "It's all about the work." Bill goes on to comment, "Mathematical papers are extremely hard to read. A single paper only five pages long may be the culmination of three years of work, which can't be read quickly and often requires significant time and energy to work through 
it line by line. This is why mathematicians struggle to thoroughly read through a few papers of immediate interest at any given time. Mathematicians as creative people work on a specific problem to the exclusion of almost everything else hate it when they are pulled from this task, and value a small close-knit network of colleagues that help pass on papers of immediate interest."

Steven Krantz (2018) commented, "Mathematics is not like biology or physics or chemistry ... A mathematician deals with ideas ... in the end, a solution to a mathematical problem comes from pure thought" (Krantz 2018, 2). Bill Ralph further commented “... mathematics has a religious feel, is an egocentric activity, is increasingly competitive and not collegial. Mathematicians live to solve problems akin to cavers exploring vast underground networks of caves of increasing complexity, size and extent. Cavers like mathematicians are constantly on a journey that finds individuals stepping through even more diverse and bigger caverns, tackling problems that cannot easily be resolved - least understood. Mathematicians push forward as explorers often drowning in ideas, questions and at times, with no hope of proving anything!" Steven Krantz (2015) echoed these sentiments that result in mathematicians' feelings of frustration and isolation, "One experiences occasional moments of giddy elation, interwoven with protracted periods of black despair. Yet this is the life path that we choose for ourselves. And we wonder why nobody understands us" (Krantz 2015, 71).

Krantz goes on to comment that mathematicians live their lives thinking about problems that they cannot solve, learning from often maddening mistakes, with the realization that "There are few outside of the mathematical community who have even the vaguest notion of what we do, or how we spend our time" (Krantz 2015, 72).

Edward Dunne in a recent Math Reviews News article (Dunne 2019) eloquently commented on the exponential growth, rapid changes, new models of publication, and increasing complexity of the mathematical literature. Academic mathematicians face personal and professional challenges, competition from colleagues, struggle to stay on top of new developments, all-thewhile fitting research into a busy academic schedule (National Research Council 2014). This study hopes to comment on mathematicians as researchers and information seekers, what they do, and how they feel about their abilities to stay on top of new and changing developments.

\section{Methodology and data collection}

\section{Research design}

This study involved a two-phased, mixed-method design. The first phase of this study involved collecting data on mathematicians' information-seeking 
behaviors, attitudes, and choices using an online survey tool, Qualtrics. The second phase of the study, initiated shortly after the completion of the survey, involved individual interviews of mathematicians at each institution. Coinvestigators collectively agreed that individual interviews in lieu of focus groups would create surroundings that were more intimate and conducive to collect better data. Each interview collected insight into survey findings, but also helped investigators explore in more depth how mathematicians conduct research, seek information, and keep on top of research, what mathematicians find important, and how they feel about these choices.

\section{Participants}

Mathematicians as faculty, staff, postdoctoral fellows, teaching staff, lecturers, graduate and doctoral students were affiliated with one of the following Canadian institutions: Brock University, Ryerson University, University of Waterloo, and Wilfrid Laurier University. All universities offer graduate-level programs, three offer doctoral programs and each institution is of similar size except the University of Waterloo which is notably larger offering internationally renowned programs. Each co-investigator, through mass e-mail invitations, recruited participants for both phases of this study. Survey participants were informed of follow-up interviews by an additional invitation embedded in the preface to the online survey instrument. Interview participants were selected to equally represent faculty and student populations.

\section{Survey design and research questions}

The online survey instrument included introductory comments, instructions, ethics-related guidelines, and co-investigator contact information. Participants were directed to answer four multiple-choice questions about their day-to-day practices tracking, documenting, and keeping up to date with news and scholarly information. The first question asked participants how successful they are with keeping up to date directed mathematicians to choose from one of three responses 1) Not Really successful, I could do better, 2) Somewhat successful, I use a variety of resources, and 3) Successful, I believe I keep on top of new and changing developments. Follow-up questions provided opportunities to collect a range of replies and "other" responses in addition to personal comments. Survey information-seeking questions included:

(1) How successful are you in keeping up to date with mathematics/ statistics news and scholarly information in your field?

(2) How do you keep up-to-date with mathematics/statistics new developments and scholarly information in your field? 
(3) Which databases do you most often use when searching the mathematics/statistics scholarly literature?

(4) Do you use a citation management system to capture, track, and document research findings and citations?

Additional demographic questions asked participants to identify their position or status, how long they have formally been involved in mathematics research, learning and/or teaching, and what area best defines their research and/or interests, choices being ranges of categories of the American Mathematical Society's 2010 Mathematics Subject Classification (MSC2010) (AMS 2019). Although mathematics as a discipline includes a wide variety of theoretical and applied subject areas, the term "mathematics" is intentionally used throughout this research study to include all types of mathematical, statistical, and applied fields of research, teaching, and learning.

\section{Interview design \& research questions}

Participants agreeing to participate in a follow-up 60-minute audio-recorded interview were asked to initially read and sign an ethics consent form. This consent form documented procedures, ethics clearance information, appropriate contact information, rights, and responsibilities of all participants. Each oneon-one interview session was conducted by a co-investigator and involved presenting selective survey findings while asking a series of semi-structured questions. Co-investigators followed ethical guidelines when conducting interviews, recording, transcribing, and vetting data, asking participants to review transcriptions for possible errors or omissions, and analyzing aggregated data for emergent trends and patterns.

Each interview intentionally followed a series of questions with co-investigators having the flexibility to skip questions, ask different follow-up and additional open-ended questions. Each interview concluded with a last question that asked how mathematicians approach their research, pursue, engage, and solve mathematical problems. This last question may help shed light on information-seeking behaviors specific to mathematics and related disciplines.

Interview questions included:

(1) Mathematicians are somewhat successful, to success, in keeping up to date with news and scholarly information. What is your experience?

(2) Keeping up to date seems to be a priority, how do you fit this into your schedule?

(3) A significant number of mathematicians feel that they are not doing a good job of keeping up to date. What are the factors at play? How does this make them feel? 
(4) Mathematicians value in-person resources such as conversing with colleagues, attending conferences, presenting papers, etc. Whom do you converse with, where, and when?

(5) Mathematicians use a variety of resources to remain current. Does this vary by position/status, length of service, and/or areas of research?

(6) Survey data suggest that mathematicians do not normally use social media, forums, relevant listservs, feeds and blogs to remain current. Why is this so?

(7) Google Scholar is a preferred database of choice. Why is this so? How do you search? What other resources do you use? Can you give examples?

(8) Mathematicians do not usually use traditional citation management system tools to capture, track, and document citations, Can you help explain this?

(9) General observations fairly or unfairly characterize mathematics as a solitary pursuit, at times frustrating, and very competitive. What are your observations?

\section{Analysis}

Using descriptive statistical analysis, we compared the similarities and differences of survey data amongst the mathematicians' information-seeking behaviors, attitudes, and choices. Qualtrics software tracks responses to multiple-choice questions providing aggregated numerical counts, percentages, basic statistical measures, and participants' comments. With this survey data, benchmarking reports were used to compare varying demographics to the study's most poignant question: "How successful are you in keeping up to date?"

Interview transcripts were vetted and pooled into a single database and analyzed using established qualitative methods. Each investigator worked independently with survey and interview datasets to code, create descriptors, and identify nascent themes. Themes and supporting data were shared amongst co-investigators, who then collectively selected and reported on the most relevant themes. Limitations of this means of analysis are acknowledged. However, the variability involved with four varying means of qualitative analysis is thought to be a strength of this study and bring validity and reliability to findings and emergent themes.

\section{Results and interpretation}

\section{Survey findings}

The survey received 142 replies in March 2019 resulting in 112 survey responses from an estimated potential target audience of 850 mathematicians. Not all participants responded to every question so total responses per question varied slightly. Participation rates at the four institutions ranged from $9.7 \%$ to $40.4 \%$ 
resulting in an overall survey response rate of $13.2 \%$. Participation rates by selfidentified participant's position included: postdoctoral fellow 5.4\%, teaching/ research/other staff 5.4\%, masters' student $10.8 \%$, doctoral student $19.8 \%$, and faculty/emeritus $58.6 \%$. Participation rates as a percentage of potential participants by position at all institutions included: masters' students $4.8 \%$, teaching/research/ other staff $5.0 \%$, doctoral students $9.6 \%$, postdoctoral fellow $11.3 \%$, and faculty/ emeritus $27 \%$. Survey participants self-identified years of research/teaching experience included: $1-5$ years $33 \%, 6-10$ years $12.5 \%, 11-15$ years $14.3 \%, 16-21$ years $13.4 \%$, and $21+$ years $26.8 \%$.

Participants' areas of research/teaching included: General/Foundations/Logic (MSC210 categories 0-3) 3.6\%, Geometry/Topology/Space (MSC2010 categories 51-58) 4.5\%, Analysis/Change and quantity/Calculus (MSC2010 categories 26-49) 12.5\%, Combinatorics/Algebra/Abstractions/Number theory (MSC2010 categories 5-22) 24.1\%, Statistics/Probability (MSC2010 categories 60-62) 26.8\%, and Applied Mathematics (MSC2010 categories 65-97) 28.6\%. Survey participation rates followed expected results with faculty and graduate students being the largest group of participants with corresponding years of experience. It was difficult to interpret whether participants' areas of research/teaching is representative of each participating institution and academic mathematics departments.

Survey participants' self-described their success in keeping up to date with mathematics news and scholarly information. A minority of mathematicians $12.5 \%$ indicated that they were successful in keeping on top of new developments in their field. Although a majority $71.4 \%$ of mathematicians believed that they were somewhat successful or successful, $28.6 \%$ indicated that they were not successful and could do better (see Table 1). Benchmarking "How successful are you in keeping up to date with information in your field" data with participant's position found that faculty on average perceive themselves as being more successful in keeping up to date than students. Although $20.0 \%$ of faculty indicated that they were not successful, a significant number of masters' $41.7 \%$ and doctoral students $45.5 \%$ self-identified as "not being as not really successful, I could do better."

Benchmarking survey data with years of research/teaching experience indicated that mathematicians with one to five years of experience (mainly students) $43.2 \%$ identified as not successful (see Table 2). A general pattern was observed that mathematicians with more experience trended toward believing themselves to be more successful with staying on top of new developments. An interview participant commented that graduate students “.. don't really know the literature ... I point grad students to books as they are better in the sense that the material is organized and consolidated and streamlined." A further interview participant commented, "Older mathematicians have networks of people, know certain journals are good filters of what to read, and what to avoid." The more experience mathematicians gain as researchers, journal referees, editors and collaborators, etc., creates greater knowledge and command of subject areas and therefore enhances informationseeking behaviors and outcomes. 


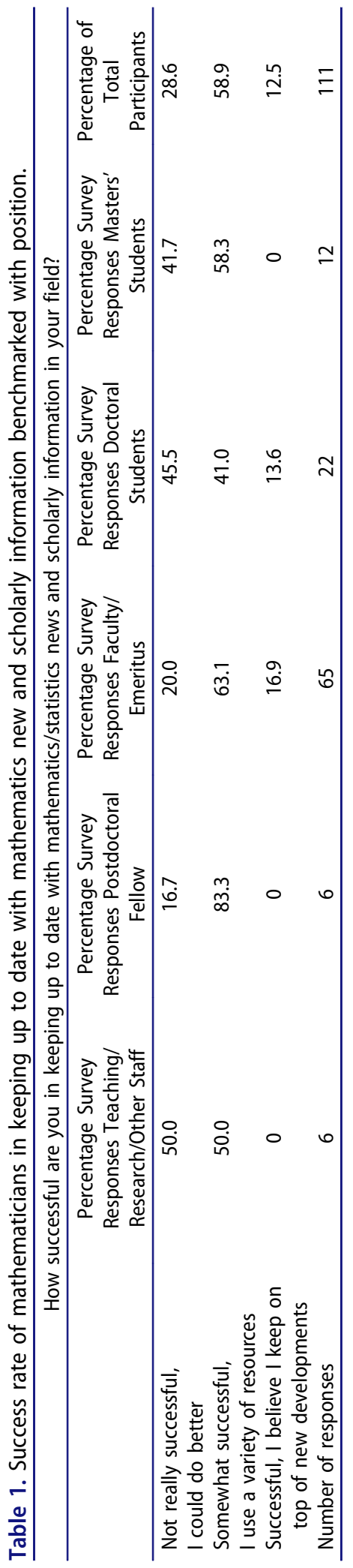




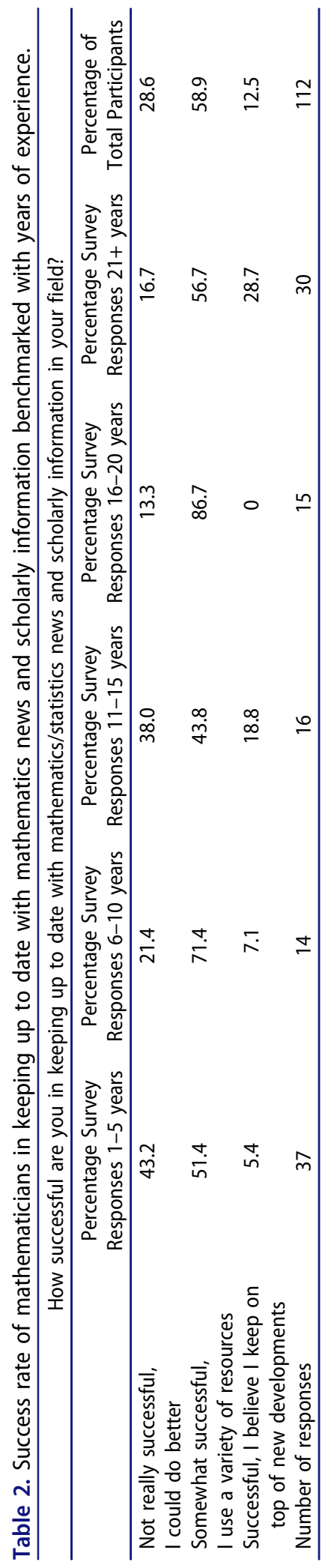


Comparing survey data with field of study failed to identify any notable trends or patterns. Although survey participants were representative of all selected MSC2010 categories, no subject area stood out as having mathematicians that were notably more successful or not successful in keeping on top of scholarly information in their field.

Benchmarking "How successful are you in keeping up to date with information in your field" data with information-seeking strategies produced interesting results (see Table 3). Mathematicians selected conversing with colleagues, attending conferences, lectures, seminars, workshops, and consulting known web or Internet sites as the most frequent and notable resources when attempting to stay on top of their research. Mathematicians that self-identified themselves as successfully keeping up to date with news and scholarly information more frequently selected consulting known web/Internet resources on a regular basis and searching scholarly databases. Survey data suggest that the majority of mathematicians engage in conversing with colleagues, attending conferences, consulting known web resources, and searching scholarly databases to remain on top of their research, albeit, some strategies more than others at different stages of their careers. Another finding is that most mathematicians may prefer, enjoy, or require direct contact when attempting to keep up to date with new developments. Survey results indicate that $73.9 \%$ of participants identified with conversing with colleagues in person, by e-mail, phone, etc., as a means to keeping up to date with information needs. It was equally interesting to observe that $22.52 \%$ of participants identified with social media tools and related online resources as a means to seek, remain, and track information as part of their information-seeking behaviors.

Survey participants based on 109 responses identified Google Scholar 68.6\%, arXiv.org. 61.5\%, MathSciNet 40.4\%, and Web of Science $13.8 \%$ as the most frequented search databases. Participants identified an additional eleven alternate search databases that included JSTOR, Scopus, and ResearchGate. For some databases, there was interesting variation when refining the results by years' experience (see Table 4). Participants with 1-5 years' experience were less likely than other groups to use arXiv 51.4\% and MathSciNet 25.7\%. While participants with 16-20 and 21+ years' experience were more likely to use MathSciNet $(60.0 \%$ and $53.3 \%$, respectively). Participants with $21+$ years' experience were also more likely to use Web of Science $26.7 \%$.

A clear majority of survey participants $(82.1 \%)$ indicated that they do not use a specific citation management system to capture, track, and document research findings and citations. Participants that did use citation management systems did not indicate a clear preference for a citation management tool, selecting or naming Mendeley, EndNote, Papers, RefWorks, Zotero, BibDesk, JabRef, and Google Scholar. Participants also mentioned LaTeXfriendly packages and BibTeX in this section, which do not have the management features librarians usually associate with citation management tools. 


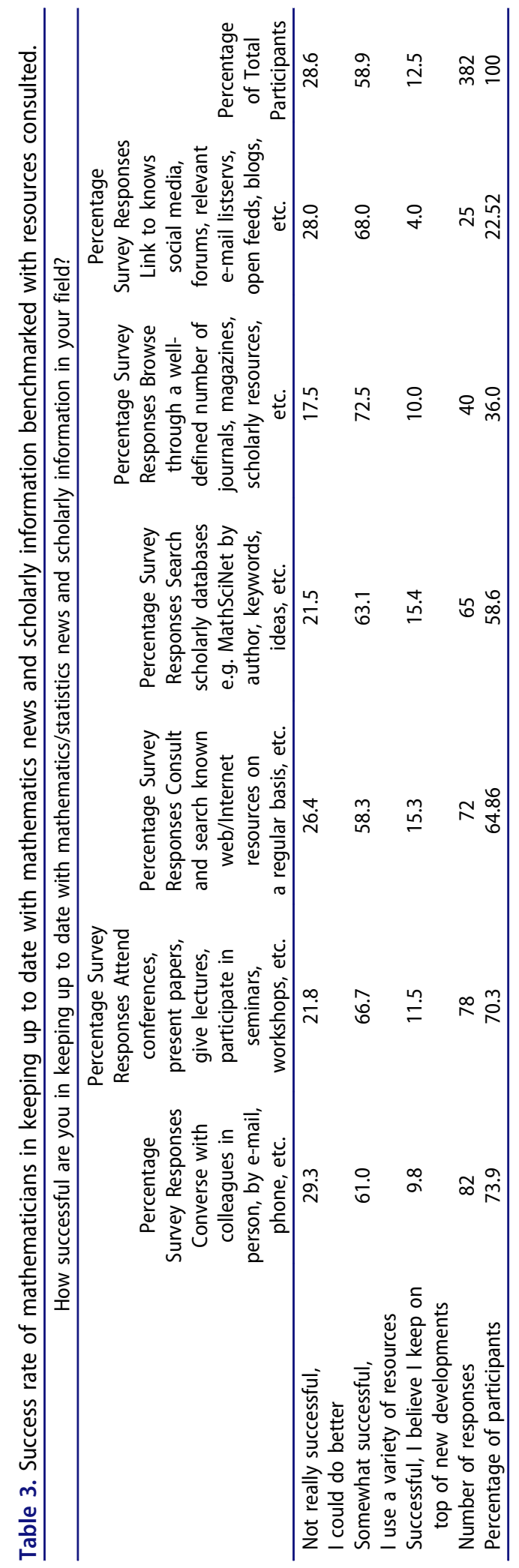




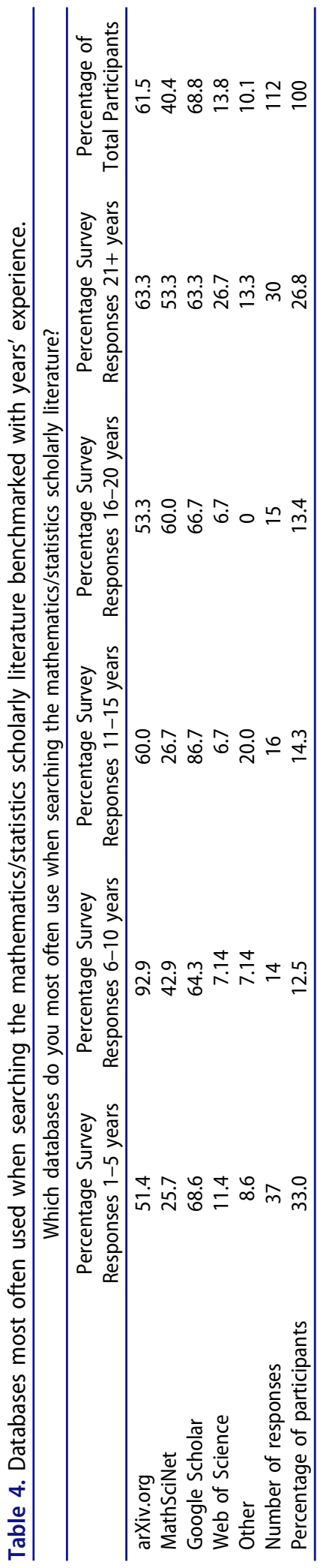


There could be many explanations for these results. For one, mathematicians may not think of data management as a priority when citing, tracking, and managing information. Citation management tools have the capacity of organizing papers, retaining comments, ideas, sharing and building literature reviews. An interview participant commented that mathematicians write few papers, are not that concerned about tracking citations and that "everyone has their own way of doing it" when it comes to managing, formatting, and documenting cited references. Another explanation could be that, although most citation management tools can import and export .bib files, many of these tools are not designed to work well within the LaTeX environment. The workarounds and extra editing required to create useful BibTeX with these tools may outweigh their overall benefits.

\section{Interview findings}

The second phase of this study involved 12 mathematicians who voluntarily participated in one-on-one interview sessions held in May and June 2019. Although all 12 participants provided rich data, there was no set number of participants to be interviewed predetermined by co-investigators. Interview participants identified by co-investigators included eight males, four females, eleven faculty members all with at least 16 years of research/teaching experience, and one doctoral student. Transcription and aggregation of audio recordings resulted in the creation of a dataset of 231 comments with 43,936 words.

\section{Emergent themes}

Using qualitative analyses, co-investigators agreed on four emergent themes including:

(1) The slower pace of math; (2) Too many papers - not enough time; (3) I could do better; and, (4) MathSciNet in a Google world.

\section{Slower pace of math}

Mathematicians value being first to communicate a new or original idea, share a mathematical proof, comment on an old theorem, present a novel solution to a problem, and/or communicate time-sensitive research. This communication happens through personal correspondence, papers published in scholarly journals, presentations at conferences, and postings of manuscripts in online preprint archive repositories, e.g., arXiv. Yet, the pace of communicating information within mathematical circles happens slowly, builds on years of experience, and can take an inordinate length of time to work itself out. Co-investigators noted that mathematics is gradual, time-consuming, protracted, laborious, and typically involves an incremental process where discovering and validating proofs are not immediately discovered or communicated to colleagues. 
A mathematician commented, "It's not a huge priority. Because math happens, so slowly ... it is an eighteen-month cycle between when you are doing research, when you are being published, and when people are reading it. In addition, no one is really working that fast. So, because it's nice and slow, like, keeping up-to-date isn't a huge priority." Because of this slower pace of progress, mathematicians may not be as concerned with keeping up to date with information needs as observed in other disciplines. This slow advancement and communication of research in mathematics may manifest itself by mathematicians conducting fewer searches, steering away from using social media, not scheduling database alerts, browsing only periodically, and keeping on top of the literature only when there is a demonstrated need.

Mathematicians reacting to the constant release of ever-increasing forms, formats, and amount of information - whether reviewing research, writing a grant proposal, overseeing student work, and/or looking back through time to note important developments - are sensitive to this slower pace of mathematical research. This pace of development may result in mathematicians exhibiting alternate seeking behaviors reflective of a very smaller universe of researchers, searching only within a subset of the literature, using well-defined search phrases and keywords, following a relatively few journals, and reading an even fewer number of papers.

Mathematicians follow a unique rhythm with respect to their narrow area of research that may result in behaviors mirroring this slower pace of development. Mathematicians may only be concerned about their world as it relates to finding solutions for individual problems. This may manifest itself by mathematicians checking in with colleagues only periodically, attending an important conference every other year, relying on in-person and informal networks to remain current and only diving into information systems to find known papers and/or check up on a named researcher's work. Mathematicians may be more dependent on developing a few close personal relationships, attending and engaging with known colleagues at conferences, and developing a rapport with a finite group of collaborators and colleagues. A mathematician commented "... so you develop these relationships, relationships and things are important because mathematics is actually hard. People are not necessarily willing to spend time helping you understand something, unless they have a relationship with you."

A mathematician commented, "The reason that researchers don't keep up to date with scholarly information from my point of view is their research is quite narrow and you wouldn't really need to look beyond your immediate search to find the [information]." Another mathematician commented, "So, yeah, there's a problem, it's being flooded by stuff, and eventually I guess it's going to be just impossible to keep up." A colleague further commented on the quality and abundance of literature "Yeah, so, I would say it's impossible 
to keep up because I would say $70 \%$ of the articles ... are probably not worth looking at."

Knowing this, mature mathematicians may feel confident in their information-seeking abilities, yet at the same time feel overwhelmed and frustrated at how inefficient it is to find something useful. A mathematician commented, "I'll read through the titles really quickly and for the areas that are really close to mine ... and when something looks very interesting I'll download the paper. It's impossible to keep up." Mathematicians may also feel apathetic to new technologies and ways of remaining current, preferring to remain satisfied with the slow pace of mathematical research, confident in their informal and narrow world of mathematics, and sticking to the task at hand of chasing ideas, creating proofs, commenting on theorems, and solutions to problems. Due to the protracted nature of the work, many mathematicians may not make information seeking a high priority.

\section{Too many papers - not enough time}

There are too many places to look, for too many papers, which takes too much time. This second theme was a common lament of all mathematicians. This conundrum leads to mathematicians being overwhelmed by the ever-increasing flow of information and not enough time to search, filter, review, and read new research. A mathematician commented, “... there is a huge amount of information so, you can't read everything. I do find I read more slowly than I used to. But, you know you pick and choose, so it's not a matter of reading everything, it's a matter of choosing wisely." Another mathematician commented “... my point is that there is so much information, even if you have access, you cannot absorb it anyways." Figuring out where best to look, incorporating new technologies and managing this dynamic is frustrating to most mathematicians. Additionally, the task of sorting out relevant researchers, sifting through new journals, evaluating the deluge of compromised, flawed, plagiarized, and less-thanstunning papers is troubling to mathematicians attempting to prioritize their time for research, creative thinking and solving problems. A mathematician commented, "Maybe they don't find it fun going looking for things or maybe there's too many places you'd have to go to so it feels overwhelming, like should I look here or should I look there?" Mathematicians reacting to this predicament may exhibit behaviors of giving up, avoidance, defaulting to simply scanning or browsing the literature, feeling no need to create alerts, performing searches only when needed, regrettably only reading papers' titles and abstracts, and relying on networks of colleagues, collaborators, and experts to help expedite this process.

These behaviors may result in feelings of inadequacy, frustration, and lack of agency. Mathematicians commented, "But it's just too much and I don't have the time to do that anymore ... It's really a matter of finding the time ... I would say [I search] fairly rarely because I am fairly focused on what I want 
immediately." A mathematician further commented, “... it should be a priority, I'm considered an expert in the field, and to be an expert I should be better educated about what's out there, and I don't feel that I necessarily am always perfectly educated ... it's very, very time consuming for a low reward in a sense." Mathematicians may benefit from leveraging online technologies and best practices to better prioritize seeking, evaluating, and managing information.

\section{I could do better}

A third theme is that a majority of mathematicians acknowledge that they feel they could do better in keeping up to date tracking new scholarly research. Mathematicians may believe that not keeping up-to-date with the literature is a reflection of an inability to manage priorities and remain organized.

The reality of keeping up to date with all that academia throws at faculty, lecturers, doctoral and graduate students too often precludes mathematicians from leveraging technologies to stay on top of new developments. These developments may lead to feelings of inadequacy, missed opportunities, and a sense that mathematicians could benefit from librarians' instruction, coaching, and incorporating best practices into their routines. A mathematician commented, "Well, time management is always an issue in this business. You have many things to do ... It is easy to let something go if you do not give it enough priority. In order to be a successful researcher, you have to think about these things a lot."

This theme could also speak to mathematicians not reaching out to embrace new ways of remaining organized, creating alerts, asking questions, and taking time to investigate ways of being more current, sustainable, and relevant. A mathematician commented, "Information seeking is not a priority for me!" A colleague commented that other priorities are paramount of importance and that most mathematicians can live just fine being less than adequate information searchers. "There wasn't really enough time and I decided that the research was important to me, that working with graduate students was important to me ... you have to decide where you think you could make the best contribution, that's best for you and your career and various other things. You can't do everything. There is an unlimited amount of ... .Some people are better than others at compartmentalizing their time. It's not easy in my opinion, if you're running something ... you've got so many things pulling at you. It gets into your head, right, and it's hard to turn that off. And if you cannot turn it off and do other things, then you have to decide, are you going to do administration or are you going to do research. There are a few people who can do both, but, nobody can do research at a really high level and do administration at a really high level at the same time ... it is just a matter of priorities and people make different choices." Clearly, mathematicians desire to be better information seekers if 
only to be more efficient allocating time, strategies and competing priorities toward effective seeking behaviors.

\section{MathSciNet in a Google world}

There has been tremendous growth in the number of mathematical databases, services, and resources that cite, track, and manage information. A fourth theme is that mathematicians are increasingly using Google-like information repositories. Mathematicians continue to value scholarly databases including Current Index to Statistics, Scopus, Web of Science, MathSciNet, and ZbMATH. However, interviewed participants were split on the value these scholarly databases bring to ongoing research. Yet, these scholarly databases are increasingly being functionally replaced by search engines and repositories such as arXiv.org, Google, Microsoft Academic Search, ResearchGate, CrossRef, Google Scholar, SQL, open and alternate BigQuery-like scalable data warehouses. Mathematicians commented that Google-like generic search engines are easier to use, dig deeper, better enable the use of natural language searching, retrieve more current research, are more convenient, and faster than traditional scholarly databases. A mathematician commented, “... wherever I post a paper, I get all these texts from my friends. They're like 'congrats. It's really cute.' Yeah, but the arXiv.org. It's up-to- date; it's quick. In math, you don't get as many bogus papers."

Mathematicians gravitating to Google-like search engines may be incorrectly perceived as being lazy, uninformed, and too easily satisfied by convenience, speed, and ease of use. Survey results indicated that $68.8 \%$ of participants use Google Scholar as their most frequented database followed by arXiv.org, then MathSciNet. Further, survey data found that only $58.6 \%$ of participants use scholarly databases to stay on top of their research. Mathematicians, similar to many scientists may use Google and other generic tools for different reasons (Grigas et al. 2017). These may include using different databases and strategies when the subject material is known, or unknown, searching for a specific paper, idea, mathematical concept or when authors are known, or not known. A mathematician commented, "I use Google Scholar if I am exploring a new area or a new trend in an area, or if I am unsure ... I find Google Scholar very useful in showing me some papers when I am unsure about what I am looking for. When I don't know who the authors should be ... " A colleague commented, "And once I have a bit more then maybe I'll use the information I have, maybe I have what I need, or maybe I'll use some of the information I gleaned from that part of the research and go and put it in MathSciNet or the arXiv or something like that. So in a sense, Google [Scholar] allows me to be imprecise at the cost of having lots of junk that has no importance whatsoever in that research."

A colleague commented on the use of different tools for different purposes using arXiv.org to find current and specific papers, using Google to browse and search when authors are not known or in new areas, and MathSciNet for historical 
and comprehensive searchers, "I chose [MathSciNet] because it is full of mathematics and it is also a longstanding resource. It has legitimacy of being around for some time. It used to be one of the resources of [first] choice. I would use MathSciNet when I was looking for a particular mathematician, but now I use Google Scholar first and MathSciNet second." Brock University's Bill Ralph commented, "It is so hard to remain current in mathematics. Google provides unique searching opportunities that ranks papers based on what people are currently reading and downloading. This is extremely valuable when searching for what's new in meeting my immediate information-seeking needs. Google's search, filter, and ranking capabilities not duplicated by other scholarly databases and search engines - saves me time."

Academic mathematicians leaning toward new generic tools may be happier, not concerned, unknowingly uninformed and/or perceive a world where information is thought to be free and open to everyone. A mathematician commented, "Graduate students don't know where to look for information, aren't mature or experienced enough in their career to be good searchers." A colleague commented, "Google Scholar is the first choice. Yeah, but I am not systematic. I usually don't go to the MathSciNet. I don't feel that I need." Another perspective involves convenience and habit, "I think it's because Google is sort of, so pervasive in our life, right? We just use Google for so many things. One advantage is it searches across multiple things, so you might have the arXiv paper and the published paper will both appear." A mathematician commented, "Google Scholar is more up-to-date ... MathSciNet is a year out of date ... so in a sense, Google allows me to be imprecise at the cost of having lots of junk that has no importance whatsoever."

Several mathematicians praised MathSciNet for its scope, reputation, inclusion of reviews, indexing capabilities, tracking of author's names, and historical record. Yet, in the face of changing information-seeking behaviors, it is uncertain whether study findings, comments and opinions, are pervasive across all mathematics subject areas, populations, and mathematicians' years of experience.

\section{Mathematics as a collegial, frustrating, and competitive pursuit}

Co-investigators were interested in mathematicians' perspectives on general observations that characterize mathematics as a solitary pursuit, frustrating, and at times very competitive. Mathematicians interviewed commented on this stereotypical observation with keen interest. A mathematician commented, “... a lot of people want to just do a lot of work on their own, and they're very competitive, but, uh, I think I'm just the opposite." Depending upon a mathematician's status, academic mathematicians are increasingly working as teams of collaborators, dependent upon the insight of colleagues to solve problems and enjoy the ongoing in-person banter that comes with active participation at conferences, lectures, and seminars. A mathematician commented, "Now, you need time alone. That is, even if I work 
with lots of people, there will be time when I want to be alone, I want to be able to have my own time to process the information, process the ideas on my own. Even when you're with collaborators you have some things and sometimes you're like yeah I need to think about this, right, I want my own time to do my own mistakes and try to really, yeah, ok. So, it's frustrating, I'm not sure if it's a solitary pursuit though solitary time is very useful."

Mathematics may be a pencil and paper solitary activity, but mathematicians “... like to share our ideas. If we do something that we think is interesting and exciting, we want other people to hear about it, we want them to think it's interesting and exciting." A mathematician commented that "Research is open ended, you have questions, you don't know if you know what you need to know, but you probably don't. You may have the wrong question. You may have to revise your question. You certainly have to add to your questions once you start answering it." Mathematicians continue to work alone, but at strategic times in the research cycle, value and need collegial insight and assistance.

Mathematics is difficult and can be frustrating. A mathematician commented that you have to "... learn to live with uncertainty. Everything you do becomes a difficult problem. You think of something, immediately, you hit a roadblock ... it's very frustrating ... you have to humble down. I mean, your ignorance is like the oceans ... everything is difficult. Some people are geniuses and can move very fast, but there are very few of those. And, even then, they will tell you they ... most of the problems are very hard to solve. So, you just humble down and do what you can. People actually write papers about what they can do but very few solve real problems because real problems are difficult." Another colleague commented, "It can be frustrating, but frustrating good. This is mathematics. You are solving problems and you love it ... but then you can take time, and are stuck until you debug your mind, it is an enjoyable frustrating. You can't be a mathematician if you don't love that because this is what happens all the time. I think this is why I am saying that it is changing because you exchange with other people and debug your mind as well in conversations ... it is not just a talk, you really sweat, you erase that white board, and then you continue ... all enjoyable [and equally difficult and frustrating] moments."

\section{Discussion and conclusions}

Through a process of collecting, analyzing, and reflecting on data, coinvestigators observed mathematicians having comparable feelings about their information-seeking behaviors. Mathematicians as creative, productive, and engaging researchers value both informal and formal means of communication. They value time alone away from people, teaching, service, and acknowledge the challenge of remaining on top of the literature.

Mathematicians value formal means of searching in structured databases, presenting papers, peer-review, sorting through prominent journals, and reviewing 
scholarly papers from established and noteworthy colleagues. Mathematicians also appreciate informal means of communication including networking with colleagues at conferences, sharing papers, ideas and conjectures by e-mail, and engaging in conversations that can help push a mathematical solution forward as a way of life. Reuben Hersch and Vera John-Seiner in the book Loving \& Hating Mathematics eloquently commented, "Mathematics is part of the broad tapestry of human thought. Like other parts of art and science, it is a search for pattern, harmony, proportion, and application. It offers dangers and frustrations, unreasonable and impossible demands. It also offers intense and memorable pleasures and satisfactions. Frustrations and satisfactions, dangers and pleasures, all are part of a deeply demanding and rewarding way of life" (Hersh and John-Steiner 2011, 338).

A previous study investigating information-seeking behaviors (Gordon et al. 2018) found chemists are somewhat similar to mathematicians in how they perceive their ability to stay on top of the literature. A minority of chemists $13.9 \%$ self-identified as being successful (versus $12.5 \%$ for mathematicians), $50.6 \%$ somewhat successful (versus $58.9 \%$ for mathematicians), and $35.5 \%$ unsuccessful (versus $28.6 \%$ for mathematicians). It is difficult to flush out why these perceptions are similar outside of disciplinary and normative practices.

Mathematicians value better tools, easier ways to communicate mathematical notations, precise language and in-person contacts echoed by Case and Given "A frequent finding is that people still turn to other people for information in the kinds of population and activities that have been examined" (Case and Given 2016, 345). These ways of engaging and working together are not easily duplicated or mimicked by search engines and big data cloud-based databases - at least not yet. A mathematician commented, "I think face-to-face discussion [that happens] in conferences [is important] and those questions you can ask directly to the speaker right there. I think that this is something that can be done only through a face-to-face interaction, attending a talk where a point of view can be conveyed in an informal and sometimes much more informative way. This [face-to-face interaction] allows mathematicians to be informed on the creation process, or why/how did you get to work on this [problem], what were the ideas that you had in mind for writing this proof, and where the inspiration comes from ... When you talk to your colleagues face-to-face then you learn much more." This type of valued conversation may contribute to the slower pace of development of mathematical proofs, communication, and papers. It may also be an important part of the mathematical research continuum.

Librarians have an important part to play serving alongside mathematicians of all abilities, experience, and subject areas. Yet, it is difficult to discern through this study whether most mathematicians view librarians as equal partners or just suppliers of avenues for discovery? This is equally true in digital library contexts 
(Kwanya 2016). Appreciating the nuances of mathematical communication, scholarship and information seeking may help position librarians to be more cognizant of discipline-specific information-seeking behaviors. Aiding mathematicians to be more productive, efficient, and successful can be a common goal. Observing mathematicians ".. treat information seeking just like any other current socioeconomic activities they are involved in; it is part and parcel of their daily norms and lifestyle....It is incumbent on libraries operating in these digital contexts to devise and implement strategies to penetrate these echo chambers to deliver information services and products which can be found through the prevailing digital information-seeking behavior" (Zha et al. 2015, 17) Librarians have a role to play addressing varied mathematicians' information-seeking behaviors if only to introduce new approaches, more appropriate resources, and better ways to manage data.

Researchers including mathematicians stand at the precipice of a series of never-ending digital revolutions where artificial systems and not human elements are driving information-seeking research. Automated relational search engines organize, interpret, and communicate scholarly research using cloudbased, artificial intelligence, machine learning and advanced search capabilities to mimic and/or replace human information-seeking behaviors. Donna Frederick in a paper titled Information Seeking in the Age of the Data Deluge commented that we are quickly "shifting away from information seeking to have information seek [us]" (Frederick 2019, 9). To better understand the social component of information seeking, related behaviors, and resultant feelings, librarians are well positioned to assist mathematicians in their never-ending goal to solve mathematical problems.

Mathematicians exhibit unique and discipline-specific informationseeking behaviors, but similar to chemists, they are equally receptive to new ways of approaching research, use of technologies and instruction to be more productive. Daniel Copenhaver (2019) commented, "The funny truth is that mathematicians really are normal people who have a different skill set than most. They are trained in logic and challenge themselves to think on really deep complicated logical subjects ... they have varying personalities, hopes, dreams, and goals just like everyone else. At their core, they function just like everyone else. Some lose sight of this because their way of thinking is valuable to many and they are put on a pedestal, but at the end of the day there isn't anything different about who they are or how they function than anyone else."

Finally, as librarians better understand, appreciate, and incorporate mathematical information-seeking behaviors within instruction and information literacy, mathematicians become more confident, less anxious, and better able to stay on top of the literature. 


\section{Acknowledgments}

We are thankful to colleagues as faculty, staff, and students that participated in this study and continue to actively serve within our academic communities. Thank you to editorial staff, reviewers' insightful comments, copy editors and colleagues that continue to be passionate about academic libraries, teaching and learning. A special acknowledgment to Brock University Associate Professor Bill Ralph's contributions to this study and friendship over a distinguished career.

\section{Disclosure statement}

The authors declare no competing financial interest. All authors have given approval to the final version of the manuscript. This paper received ethics clearance from all participating institutions' boards including the Brock University Social Science Research Ethics Board file 18-111 GORDON.

\section{ORCID}

Ian D. Gordon (1D http://orcid.org/0000-0003-1128-3301

Brian D. Cameron (1) http://orcid.org/0000-0001-8646-6490

Debbie Chaves (i) http://orcid.org/0000-0003-3840-1902

Rebecca Hutchinson (D) http://orcid.org/0000-0002-3773-0192

\section{References}

Agarwal, N. K. 2018. Exploring context in information behavior: Seeker, situation, surroundings, and shared identities. San Rafael, CA: Morgan \& Claypool.

AMS. 2019. 2010 mathematics subject classification. Providence, RI: American Mathematical Society. https://mathscinet.ams.org/mathscinet/msc/msc2010.html.

Anglada, L., and Á. Borrego. 2016. Faculty information behaviour in the electronic environment: Attitudes towards searching, publishing and libraries. New Library World 117 (3/4):173-85. doi:10.1108/NLW-11-2015-0089.

Brown, C. M. 1999. Information seeking behavior of scientists in the electronic information age: Astronomers, chemists, mathematicians, and physicists. Journal of the American Society for Information Science 50 (10):929-43. doi:10.1002/(SICI)1097-4571(1999)50:10<929::AID-ASI8> 3.0.CO;2-G.

Brown, N. M. 1985. Thinking like a mathematician. University Park, PA: Penn State University. http://news.psu.edu/story/141474/1985/03/01/research/thinkingmathematician.

Bussell, H., J. Hagman, and C. S. Guder. 2017. Research needs and learning format preferences of graduate students at a large public university: An exploratory study. College \& Research Libraries 78 (7):978-98. doi:10.5860/crl.78.7.978.

Byers, W. 2007. How mathematicians think: Using ambiguity, contradiction, and paradox to create mathematics. Princeton NJ: Princeton University Press.

Casazza, P. G., S. G. Krantz, and R. D. Ruden. 2015. I, mathematician. Washington, DC: Mathematical Association of America.

Case, D. O., and L. M. Given. 2016. Looking for information: A survey of research on information seeking, needs, and behavior. 4th ed. Bingley, England: Emerald Group. 
Catalano, A. 2013. Patterns of graduate students' information seeking behavior: A meta- synthesis of the literature. Journal of Documentation 69 (2):243-74. doi:10.1108/00220411311300066.

Choo, C. W. 2006. How we come to know: Understanding information-seeking behavior. In The knowing organization: How organizations use information to construct meaning, create knowledge, and make decisions, 2nd ed., 29-74. NY: Oxford University Press.

Cole, C. 2017. Looking for information: A survey of research on information seeking, needs, and behavior. Journal of the Association for Information Science \& Technology 68 (9):2284-86. doi:10.1002/asi.23778.

Copenhaver, D. 2019. Are mathematicians normal people? Quora. https://www.quora.com/ Are-mathematicians-normal-people.

Davis, P. J., R. Hersh, and E. Marchisotto. 2012. The mathematical experience. ed. study. Boston: Birkhäuser.

Dehaene, S. 1997. The number sense: How the mind creates mathematics. revised and updated ed. NY: Oxford University Press.

Dinet, J., A. Chevalier, and A. Tricot. 2012. Information search activity: An overview. European Review of Applied Psychology 62 (2):49-62. doi:10.1016/j.erap.2012.03.004.

Dunne, E. 2019. Looking at the mathematics literature. Notices of the American Mathematical Society 66 (2):227-30. https://www.ams.org/journals/notices/201902/rnoti-p227.pdf.

Ellis, D. 1989a. A behavioural approach to information retrieval system design. Journal of Documentation 54 (3):171-212. doi:10.1108/eb026843.

Ellis, D. 1989b. A behavioural approach to information retrieval system design. Special issue. Journal of Information Science 15 (4/5):237-47. doi:10.1177/016555158901500406.

Ellis, D. 1993. Modeling the information-seeking patterns of academic researchers: A grounded theory approach. The Library Quarterly 63 (4):469-86. doi:10.1086/602622.

Ellis, D., D. Cox, and K. Hall. 1993. A comparison of the information seeking patterns of researchers in the physical and social sciences. Journal of Documentation 27 (1):31-41. doi:10.1108/eb026919.

Erickson, M. J. 2011. Beautiful mathematics. Washington, DC: Mathematical Association of America.

Falciani-White, N. 2012. Understanding information seeking behavior of faculty and students: A review of the literature. In Planning and implementing resource discovery in academic libraries, ed. M. Pagliero Popp and D. Dallis, 1-21. Hershey, PA: IGI Global. doi:10.4018/978-1-4666-1821-3.ch001.

Falciani-White, N. 2016. Understanding the "complexity of experience": Modeling faculty research practices. The Journal of Academic Librarianship 42 (2):118-26. doi:10.1016/j. acalib.2016.01.003.

Fisher, K. E., and H. Julien. 2009. Information behavior. Annual Review of Information Science and Technology 43 (1):1-73. doi:10.1002/aris.2009.1440430114.

Fitzgerald, M., and I. M. James. 2007. The mind of the mathematician. Baltimore, MD: Johns Hopkins University Press.

Fitzgerald, S. R. 2018a. Serving a fragmented field: Information seeking in higher education. The Journal of Academic Librarianship 44 (3):337-42. doi:10.1016/j.acalib.2018.03.007.

Fitzgerald, S. R. 2018b. The role of affect in the information seeking of productive scholars. The Journal of Academic Librarianship 44 (2):263-68. doi:10.1016/j.acalib.2018.01.001.

Frederick, D. E. 2019. Information seeking in the age of the data deluge. Library Hi Tech News 36 (2):6-10. doi:10.1108/LHTN-10-2018-0065.

Ge, X. 2010. Information-seeking behavior in the digital age: A multidisciplinary study of academic researchers. College \& Research Libraries 71 (5):435-55. doi:10.5860/crl-34r2. 
Gordon, I. D., P. Meindl, M. White, and K. Szigeti. 2018. Information seeking behaviors, attitudes, and choices of academic chemists. Science \& Technology Libraries 37 (2):130-51. doi:10.1080/0194262X.2018.1445063.

Greenberg, R., and J. Bar-Ilan. 2017. Library metrics - Studying academic users' information retrieval behavior: A case study of an Israeli university library. Journal of Librarianship \& Information Science 49 (4):454-67. doi:10.1177/0961000616640031.

Grigas, V., S. Juzeniene, and J. Velickaite. 2017. "Just Google it"-The scope of freely available information sources for doctoral thesis writing. Information Research: An International Electronic Journal 22 (1). http://www.informationr.net/ir/22-1/paper738.html.

Hadamard, J. 1996. The mathematician's mind: The psychology of invention in the mathematical field. Princeton, NJ: Princeton University Press.

Heaton, L. 2017. A brief history of mathematical thought. NY: Oxford University Press.

Hersh, R., and V. John-Steiner. 2011. Loving + hating mathematics: Challenging the myths of mathematical life. Princeton, NJ: Princeton University Press.

Hoyles, C., and H. Wilson. 2016. Mathematics: A living, changing landscape. In Mathematics: How it shaped our world, ed. D. Rooney, 187-91. London: SCALA.

Hunt, S. L., and C. J. Bakker. 2018. A qualitative analysis of the information science needs of public health researchers in an academic setting. Journal of the Medical Library Association 106 (2):184-97. doi:10.5195/JMLA.2018.316.

Jordan, J. L. 2013. Meta-synthesis of the research on information seeking behaviour of graduate students highlights different library resource needs across disciplines and cultures. Evidence Based Library and Information Practice 8 (4):132-35. doi:10.18438/ B8MK7V.

Khazer, M., and S. A. Ganaie. 2018. Impact of technology on information seeking behavior: A case with post graduate students of select universities in Jammu and Kashmir. Fifth International Symposium on Emerging Trends and Technologies in Libraries and Information Services (ETTLIS), Nodia, India, pp. 254-58. doi:10.1109/ETTLIS.2018.8485272.

Krantz, S. G. 2015. Through a glass darkly. In I, mathematician, ed. P. G. Casazza, S. G. Krantz, and R. D. Ruden, 71-85. Washington, DC: Mathematical Association of America.

Krantz, S. G. 2018. Essentials of mathematical thinking. Boca Raton, FL: CRC Press.

Kuhlthau, C. C. 1993. A principle of uncertainty for information seeking. Journal of Documentation 49 (4):339-55. doi:10.1108/eb026918.

Kuhlthau, C. C. 2004. Seeking meaning: A process approach to library and information services. 2nd ed. Norwood, NJ: Ablex.

Kwanya, T. 2016. Information seeking behaviour in digital library contexts. In Information seeking behavior and challenges in digital libraries, ed. A. Tella, 1-25. Hershey, PA: Information Science Reference.

Mason, J., L. Burton, and K. Stacey. 2010. Thinking mathematically. 2nd ed. Harlow, UK: Pearson.

National Research Council. 2013. The mathematical sciences in 2025. Washington DC: The National Academies Press. https://doi.10.17226/15269.

National Research Council. 2014. Developing a 21st century global library for mathematics research. Washington, DC: The National Academies Press. https://ArXiv.org/ftp/ArXiv/ papers/1404/1404.1905.pdf.

Nicholas, D., C. Boukacem-Zeghmouri, B. Rodríguez-Bravo, X. Xu, A. Watkinson, A. Abrizah, E. Herman, and M. Świgoń. 2017. Where and how early career researchers find scholarly information. Learned Publishing 30 (1):19-29. doi:10.1002/leap.1087. 
Niu, X., and B. M. Hemminger. 2012. A study of factors that affect the information-seeking behavior of academic scientists. Journal of the American Society for Information Science and Technology 63 (2):336-53. doi:10.1002/asi.21669.

Niu, X., B. M. Hemminger, C. Lown, S. Adams, C. Brown, A. Level, M. McLure, A. Powers, M. R. Tennant, and T. Cataldo. 2010. National study of information seeking behavior of academic researchers in the United States. Journal of the American Society for Information Science and Technology 61 (5):869-90. doi:10.1002/asi.21307.

Pettigrew, K. E., R. Fidel, and H. Bruce. 2001. Conceptual frameworks in information behavior. Annual Review of Information Science and Technology 35:43-78.

Pontis, S., A. Blandford, E. Greifeneder, H. Attalla, and D. Neal. 2017. Keeping up to date: An academic researcher's information journey. Journal of the Association for Information Science and Technology 68 (1):22-35. doi:10.1002/asi.23623.

Robson, A., and L. Robinson. 2013. Building on models of information behaviour: Linking information seeking and communication. Journal of Documentation 69 (2):169-93. doi:10.1108/00220411311300039.

Ruelle, D. 2007. The mathematician's brain. Princeton NJ: Princeton University Press.

Sahu, H. K., and S. Nath Singh. 2013. Information seeking behaviour of astronomy/astrophysics scientists. Aslib Proceedings 65 (2):109-42. doi:10.1108/00012531311313961.

Sapa, R., M. Krakowska, and M. Janiak. 2014. Information seeking behaviour of mathematicians: Scientists and students. Information Research 19 (4):301-20. http://informationr. net/ir/19-4/paper644.html\#.Xe6nAehKjcs.

Savolainen, R. 2018. Pioneering models for information interaction in the context of information seeking and retrieval. Journal of Documentation 74 (5):966-86. doi:10.1108/JD-112017-0154.

Shah, C. 2017. Social information seeking: Leveraging the wisdom of the crowd. Cham, Switzerland: Springer.

Tegmark, M. 2014. Our mathematical universe: My quest for the ultimate nature of reality. NY: Knopf.

Walliman, D. 2017. The map of mathematics. https://dominicwalliman.com/; https://www. youtube.com/watch? $\mathrm{v}=\mathrm{OmJ}-4 \mathrm{~B}-\mathrm{mS}-\mathrm{Y}$.

Wellings, S., and B. Casselden. 2019. An exploration into the information-seeking behaviours of engineers and scientists. Journal of Librarianship and Information Science 51 (3):789-800. doi:10.1177/0961000617742466.

Wilson, T. D. 1997. Information behaviour: An interdisciplinary perspective. Information Processing \& Management 33 (4):551-72. doi:10.1016/S0306-4573(97)00028-9.

Zha, X., W. Wang, Y. Yan, J. Zhang, and D. Zha. 2015. Understanding information seeking in digital libraries: Antecedents and consequences. Aslib Journal of Information Management 67 (6):715-34. doi:10.1108/AJIM-12-2014-0167. 